\title{
Degradable Nanocomposite Preformed Particle Gel For Chemical Enhanced Oil Recovery Applications
}

\section{Paul Tongwa ${ }^{\mathrm{a}}$, Bai Baojun ${ }^{\mathrm{a}}$}

a. SPE, Missouri University of Science and Technology, Department of Petroleum Engineering, 1870 Miner Circle, Rolla MO, 65409

Corresponding author Bai Baojun; Tel: 573-341-4016; Fax: (573) 341-6935; Email: baib@mst.edu

\section{Summary}

In this work, we present a preformed particle hydrogel with a more superior performance than conventional hydrogels with potential conformance control applications in mature oilfields. Preformed particle hydrogel was designed by the reaction of monomer, initiator, crosslinker, additives, and Laponite XLG nanoclay, whereas conventional hydrogel is designed from just monomer, initiator, crosslinker and additives. The presence of nanomaterial in hydrogel design affords it tremendous improvement in nanocomposite gel properties and behavior compared to conventional hydrogels without any nanomaterial. On incorporation of nanomaterial, increase in gel strength of up to $394 \%$ was observed. Additionally, swelling performance, post-degraded gel viscosity, and long-term thermal resistance of nanocomposite gel increased by several orders of magnitude compared to hydrogels with no nanomaterial. Environmental Scanning Electron Microscopy (ESEM) revealed the presence of a very dense 3-D network compared to hydrogels with no nanomaterial. It was observed that after degradation, nanocomposite hydrogel had a post-degradation viscosity of $4437 \mathrm{cp}$ whereas hydrogel with no nanomaterial had a postdegradation viscosity of $170 \mathrm{cp}$. Thus, degradable Laponite XLG nanocomposite hydrogels are recommended for secondary polymer flooding, since they have a high post-degradation viscosity under anaerobic conditions. 


\section{Introduction and background}

The fact that the oil and gas industry is spending a lot of money and using every available cutting-edge technology to find oil in very risky and unfavorable terrains such as the deep seas and polar regions of the earth is a pointer to the fact that primary and secondary oil production from existing fields is reaching peak production. However, these existing fields still contain significant and unrecoverable quantities of hydrocarbons which cannot be recovered by current available technologies. Rather than explore for oil in such risky terrains, why not optimize oil production from already existing, mature fields which have a well known production history and performance? Such enormous and untapped amount of hydrocarbons in already existing, mature, left-behind fields is the goal of Enhanced Oil Recovery (EOR, also called tertiary production). EOR methods are crucial to a continuous world supply of oil.

As reservoirs mature, oil production declines while water production rises. Excess and unwanted water production from these mature fields is one problem that has plagued the oil industry for decades. Excess water production is a frequent problem that occurs in mature reservoirs as a result of longterm water-flooding. Such excess water production usually results in increased environmental concerns, increased levels of corrosion and scale and ultimately leads to early shut-in of wells that still contain significant volumes of hydrocarbons (Liu et al. 2006; Bai et al. 2007a).

One fundamental reason for a decline in oil production with time is because of the existence of fractures and permeability variations that exist between the different layers of the reservoir. Fractures present a water-thief zone through which injected flood water channels through, from the injector to the producer, thereby leaving hydrocarbons in the low permeability (non-fractured) zones untouched. The injected flood water follows the path of least resistance 
(high permeability zones), bypassing large amount of oil in low permeability matrix. This leads to increased, unwanted water production and poor oil recovery. Therefore, plugging reservoir fractures and thus correcting reservoir heterogeneity (that is conformance control), is key to an increased oil production, and hence the reason for this work.

In an attempt to mitigate excess water production and hence increase hydrocarbon production, hydrogels are often injected near wellbore or far-wellbore to preferentially seal fractures or higher permeability zones (Tongwa et al. (2013a, 2013b); Bai et al. (2007b, 1999, 2008); Liu et al. 1999). Hydrogels as fracture-plugging and fluid diverting materials have been employed in conformance control (profile modification) and in the control of excess water production during EOR applications (Bai et al. (1999, 2007a, 2007b, 2008); Zhang et al. 2011; Vossoughi (2000); Wang et al. (2001, 2003)). Mechanistically, hydrogel is injected to seal high permeability and fracture zones, such that when injected fluids are injected, they will be forced or redirected to the low permeability, unswept oil-rich zones, sweeping out oil from them, leading to additional oil production. This, in summary, is the goal of any gel treatment work. This process is called profile modification or permeability modification. As the term implies, the process seeks to even out or correct the sharp difference in permeabilities that exist in the different formation layers, creating a homogeneous reservoir.

Over the years, different types of gel treatments have been utilized in an attempt to solve conformance control problems. Initially, industry started using in-situ gels in which gelling solution is injected into reservoir and crosslinking of gelling solution to form 3-D bulk gel occurs downhole. This technology was quickly dropped due to its inherent disadvantages such as selective injectivity, possible damage to low permeability zones, dispersion and dilution of 
gelant, syneresis, dehydration, and inadequate control of gelation time (Seright, 1990; Young et al. 1988; Asghari, 1999; Bryant et al. 1996; Willhite et al. 1986).

In an attempt to overcome the various limitations of in-situ gel technology, industry experts and researchers developed a novel technology to address conformance control problems called preformed gel technology. Preformed gels are three-dimensional, hydrophilic crosslinked polymers, which in contact with water, swell but do not dissolve as a result of a chemical or physical crosslinking and often than not will undergo a volume phase change when surrounding conditions such as temperature, salinity or $\mathrm{pH}$ change (Wen-Fu et al. 2006; Kytai and Jennifer 2002). The novelty and main difference between this technology and in-situ gel technology is that with preformed gel, gel formation takes place at the surface, well ahead before injection, whereas with in-situ gelation, crosslinking and gel formation occurs downhole in the reservoir (Bai et al. 2013; Frampton et al. 2004). This technology was revolutionary in that it addressed some of the problems posed by in-situ gelation such as dilution and dispersion of gelant, chromatographic separation of gelant solution, dehydration, syneresis, and most importantly damage of low permeability zones.

However, despite the tremendous advantages of preformed gels over in-situ gels, preformed gels have not as yet provided an all encompassing solution to the problem of conformance control and reservoir heterogeneity. Some of the limitations of preformed gels include: (a) Mechanical: inadequate strength and toughness, (b) thermal: inadequate thermal resistance to withstand very extreme reservoir conditions, shorter degradation time, (c) swelling: inadequate swelling ability, (d) elasticity: inadequate gel elasticity. 
Thus, there is a present need to provide a technology that surpasses the performance of current preformed gel technology. The current work is an extension of existing preformed gel technology by the incorporation of nanomaterials in gel design for improved mobility control.

We propose a degradable nanocomposite Preformed Particle Gel, called nanocomposite PPG, which involves the incorporation of nanoclay in it. The incorporation of nanomaterials not only overcomes prior limitations of conventional preformed gels such as poor long-term thermal stability and inadequate mechanical strength, but results in improvement in gel performance and properties to withstand adverse and extreme reservoir conditions, and also in improvement in post-degradation gel viscosity after the gel degrades under reservoir conditions. The novelty of this work involves a dramatic increase in post-degradation gel viscosity compared to currently existing gels without nanomaterials (Figure 1).

This product, when injected into the reservoir, will initially act as a conformance control agent by plugging water-thief zones and channels, thereby directing injected water to sweep out oil from low permeability oil-rich zones. After an extended time period, this product degrades into a highly viscous polymer solution which then moves deeper into the reservoir, mixes with flood water and increases its viscosity, and by so doing improves water and polymer flooding processes by increasing water sweep efficiency, thereby enhancing oil production. Therefore, the viscosity of the gel after it degrades is of key concern (Figure 2).

The general scheme of this work includes the following processes: 1) preparing crosslinked nanocomposite PPGs with a predetermined size, 2) dispersing the nanocomposite PPGs into a brine solution to form swelled PPGs, 3) injecting the swelled nanocomposite PPGs into the target reservoir, 4) The following treatment after PPGs injection such as water flooding, 
polymer flooding or SP flooding etc can be performed to improve the oil recovery by reducing the excess water production, and 5) After certain amount of period, the decomposition of the injected nanocomposite PPGs eventually through the hydrolysis induced by heat or $\mathrm{pH}$ into high viscosity linear polymer solution for the secondary polymer flooding to further enhance the oil recovery.

Conventional preformed gel synthesis involves a multi-component reaction that incorporates monomer, initiator, and cross-linker. However, our nano-PPG synthesis involves a multi-component reaction that incorporates monomer, initiator, cross-linker, and nano-material (Figure 3).

\section{Materials and Methods}

\subsection{Materials}

Monomer used in this study, acrylamide, AM (98.5\%), was purchased by Alfa Aesar company (Ward Hill, MA) as a white granular solid and is completely water soluble. It was used as received. Crosslinker used is Polyethylene glycol diacrylate (PEG-200) purchased from Sigma Aldrich company. Nanoclay used in this study, Laponite XLG (L-XLG) was received with courtesy from Southern Clay Products (SCP) Inc. Potassium persulfate $\left(\mathrm{K}_{2} \mathrm{~S}_{2} \mathrm{O}\right.$, KPS) as redox initiator was employed to polymerize the monomer solutions of acrylamide and were purchased from Sigma Aldrich company. Sodium Chloride, $\mathrm{NaCl}$ (99.8\%) was purchased from Fisher Scientific Inc. and used as received. Distilled water was used for the synthesis while $1 \%$ brine solution and formation water were used for swelling experiments.

The following is one example to illustrate the synthesis process for nano-composite gels. First, $30 \mathrm{~g}$ of AM was dissolved in $100 \mathrm{~g}$ of distilled water in a double-necked flat-bottomed 
reactor equipped with inlet and outlet tubes for nitrogen gas. The mixture was stirred at room temperature for 10 minutes. Then $0.2 \%(0.26 \mathrm{~g})$ of Laponite XLG was added to the solution and stirred vigorously for about 24 hours to ensure complete exfoliation of clay nanomaterial. Then, 250 ppm of the labile crosslinker PEG-200 was added to the mixture and stirred for 10 minutes. The mixed solution was then purged with nitrogen gas for 30 minutes before 100 ppm of KPS initiator was added to the solution. This resulting solution was kept for 10 hours at $40^{\circ} \mathrm{C}$ in a water bath to ensure complete gelation. The strong and elastic bulk gel formed was cut into small pieces. It was then purified by soaking in a large amount of distilled water for three days to remove the unreacted monomers and additives, followed by drying in an oven at $60^{\circ} \mathrm{C}$ until the weight could not change any more. The dried gel solids were crushed into very small particle sizes, called preformed particle gels (PPGs), by blending in a blender machine (Black \& Decker). PPGs with the particle size between $80-100$ mesh $(180 \mu \mathrm{m}-250 \mu \mathrm{m})$ were selected through the standard testing sieves (Fisher Scientific Company) for further characterization and evaluation. For gels with no nanomaterial, the same procedure was followed except that nanoclay was excluded.

\subsection{Methods}

The following properties were evaluated for the nanocomposite gels:

Swelling kinetics: The essence of swelling measurements is to ascertain the maximum swelling capacity of gels in order to determine its ability to swell and plug reservoir fractures and high permeability matrices. A $1 \%$ gel solution was prepared by immersing 0.25 grams of the dry particle gel in 24.75 grams of $1 \% \mathrm{NaCl}$ brine solution and formation water respectively. The Swelling ratio of the gels was calculated from the following equation: 
Swelling Ratio $=\mathrm{V}_{\mathrm{s}} / \mathrm{V}_{\mathrm{i}}$

Where, $\mathrm{V}_{\mathrm{i}}$ is the volume of dry gel and,

$\mathrm{V}_{\mathrm{s}}$ is the volume of swollen gel

Gel strength (Rheology) test: The rheological properties of hydrogels were measured using a Haake RheoScope RO1 version 3.61.0000 from Thermo Scientific. The sensor used for all measurements was PP20 with a gap of $2 \mathrm{~mm}$. The samples were cut in uniform dimensions with diameter of $2 \mathrm{~cm}$ and height of $2 \mathrm{~mm}$. The measurements were set as an oscillation model and frequency experiments were first performed in the range of $1-15 \mathrm{~Hz}$ in order to establish the extent of the linear viscoelastic region. Based on the data, all subsequent oscillation timedependent experiments were performed at a fixed frequency of $1 \mathrm{~Hz}$ and controlled stress (CS) of 1.0 Pa to obtain the values of G' and G' as a function of time. All runs were repeated at least three times.

Thermostability tests: Long-term thermal stability testing were carried out in the key apparatus shown in Figure 4. First, 0.12 grams of dry particle gels were measured into each ampoule, and then 11.88 grams of brine $(1.0 \mathrm{wt} \% \mathrm{NaCl})$ solution was injected into each ampoule. Therefore, the gel concentration was set at $10,000 \mathrm{ppm}$ and 12 grams total for each ampoule. The ampoules were placed one at a time into the manifold. The valves were closed, and a vacuum pump was started. After the ampoules had been attached to the manifold, each valve was slowly opened one at a time in order to minimize any rush of liquid or gas out of the ampoule into the manifold. The vacuum pump continued to run at $-25 \mathrm{psi}$ for about half an hour to remove the dissolved gases in the liquid sample, including any trace of dissolved oxygen that might have remained in the sample. Next, the ampoules were flame sealed in place. The sealed ampoules were weighed using an analytical balance with an accuracy of 0.0001 grams and then placed in an oven and aged at $45^{\circ} \mathrm{C}, 60^{\circ} \mathrm{C}$ and $80^{\circ} \mathrm{C}$. After the specified aging times, one 
ampoule was taken out of the oven and cooled to room temperature. This ampoule was reweighed to confirm that none of the solution had leaked. A loss of about 0.001 grams or more indicated possible leakage from this ampoule. In that case, another ampoule would be used for a post-aging measurement.

Environmental SEM Evaluation: Environmental Scanning Electron Microscopy (ESEM) studies were employed to study the porous network structure of the gel. This gives information about pore-interconnectivity and swelling propensity. After the particle gels were completely swollen in brine, ESEM was used to examine the surface morphology of the swollen particle gel. Swollen nano-PPG samples were mounted on metal stubs at a low vacuum degree (4.6 Torr), and a relatively low temperature (near $0^{\circ} \mathrm{C}$ ) was observed. The samples first underwent a freeze process in the chamber of an FEI Quanta 600 FEG extended vacuum scanning electron microscope. To emphasize the gel microstructure, the following ESEM imaging protocol was followed: the temperature and pressure were decreased simultaneously from $0^{\circ} \mathrm{C}$ and 4.6 Torr to $-5^{\circ} \mathrm{C}$ and $2-3$ Torr, thereby freezing the sample; the temperature was then allowed to rise to $20^{\circ} \mathrm{C}$ with a rate of $2^{\circ} \mathrm{C} /$ minute at $2-3$ Torr pressure to sublimate water from the sample at a relative humidity of $12.5 \%$.

Viscosity measurements: The viscosity of nanocomposite PPG after thermal degradation was measured. After an extended time period, gel degrades into a viscous polymer solution. This viscous polymer solution will then move into deeper regions of the reservoir to increase the viscosity of the flood water and boost polymer flooding process. Thus the higher the post-degradation gel viscosity, the better its ability to improve polymer flooding process. The viscosity of the degraded solution was measured using a Brookfield viscometer with a shear rate 
of 0 RPM to 100 RPM using a \#18 or \#34 spindle. The viscosity measured at 6 RPM was recorded as the reported value.

\section{Results and Discussion}

A detailed vis-à-vis comparison of currently existing and novel nanocomposite hydrogels reveals that the latter far supersedes existing hydrogels in terms of product performance and usefulness. A summary of the results obtained for the different tests carried out are presented below.

\subsection{Improvement in Mechanical Performance of Nanocomposite Hydrogel Compared to Hydrogel with no Nanomaterial}

The rheology behavior of LXLG nanocomposite hydrogels and hydrogels with no nanomaterial were studied. The mechanical strength of a gel often can be estimated by its viscoelastic properties such as elastic modulus $\left(G^{\prime}\right)$. The variation in elastic modulus $\left(G^{\prime}\right)$ with time for LXLG nanocomposite hydrogel with $0.2 \%, 0.6 \%$, and $3 \%$ nanomaterial is presented in Figure 5 and is compared against hydrogel without nanomaterial. It is observed from Figure 5 that the elastic modulus significantly increases with increasing nanomaterial concentration. The elastic modulus of hydrogel with no nanomaterial is at lowest value of $800 \mathrm{~Pa}$. Clearly, an increase in gel strength is observed as LXLG nanomaterial is introduced.

Additionally, measurements were done for both dry gels and for gels swollen in $1 \% \mathrm{NaCl}$ solution (hydrogels were swollen until they could rise no further). The reason for this measurement was to ascertain by how much gel strength decreased after gel swelled. Results indicate that after swelling, gel strength decreased by $1.8 \%$ for gels containing $0.2 \%$ LXLG nanomaterial, by $11.1 \%$ for gels containing $0.6 \%$ LXLG nanomaterial, and by $5.6 \%$ for gels containing 3\% LXLG nanomaterial. For gels with no nanomaterial, gel strength decreased by 
$11.8 \%$ after swelling. As gels absorb water, their crosslink density decreases, hence they swell. Hydrogel without nanomaterial swelled the most, since it has no re-enforcing crosslink network provided by the addition of nanomaterial. As expected, 3\% LXLG hydrogel with the most amount of nanomaterial swelled the least. The additional crosslink networks provided by the higher nanomaterial concentration resisted excessive swelling.

\subsection{Improvement in Swelling Performance Compared to Gel with no Nanomaterial}

Figure 6 presents the swelling behavior of nanocomposite hydrogel and hydrogel with no nanomaterial swelled in $1 \%$ brine and formation water respectively. In both solutions, we observe a clear increase in swelling kinetics when nanomaterial was introduced into hydrogel. In formation water, a maximum increase of $180 \%$ was observed between no nanomaterial gel and gel with $0.2 \%$ nanomaterial. Additionally, it was observed that swelling ratio decreased with increasing nanomaterial concentration. A plausible explanation for this phenomenon could be because with increasing nanoclay concentration above a particular threshold, more nanomaterials participate in gelation reaction, occupying hydrogel pore spaces and preventing excessive absorption of water and hence swelling. In $1 \%$ brine solution however, a maximum increase in swelling performance of $412 \%$ was observed.

\subsection{Improvement in Thermal Resistance Compared to Hydrogel with no Nanomaterial}

Once injected downhole into fractures or high permeability streaks, the longterm thermal resiliency of hydrogels to continuously seal fractures under adverse reservoir conditions is important. Without longterm endurance, gels rapidly degrade, leading to a re-opening of an already sealed fracture, thus re-creating a water-thief channel. Therefore, ensuring hydrogels can adequately seal fractures over a prolonged period of time is paramount. Figure 7 presents 
longterm thermal stability testing of hydrogels in both $1 \%$ brine and formation water. As is clearly seen from Figure 7, hydrogels with no nanomaterial rapidly degraded within days whereas for hydrogels with nanomaterial, degradation occurred over a year in some cases and in others hydrogels have not degraded yet. Additionally, we observed that an increase in nanomaterial concentration led to an increase in long-term thermal resistance of hydrogels. This is as expected because increasing nanomaterial concentration leads to an increased participation of nanomaterial in the gelation process, affording a stronger gel. Such dramatic improvement in long-term thermal stability of nanocomposite hydrogels is one key reason we believe they are potentially valuable in conformance control applications.

\subsection{Improvement in Post-degradation Viscosity Compared to Gel with no Nanomaterial}

The present invention provides a new and improved method combining gel treatment and polymer flooding processes during an oil recovery operation. In one hand, the inventive LXLG nanocomposite PPG can serve as a plugging agent for a designed and controlled period to improve conformance control so that more oil may be swept out of the low permeability formation pores to the production well.

On the other hand, depending on the reservoir temperature, $\mathrm{pH}$ value, and/or formation water salinity, the LXLG nanocomposite PPG eventually and completely decompose through hydrolysis into linear polymer chain solutions. This resulting polymer solution can then move into the reservoir formation to perform the polymer flooding. Figure 8 presents a picture of LXLG nanocomposite hydrogels both before and after their degradation in both aerobic and anaerobic environment. 
The novelty of this work involves the dramatic increase of the viscosity of the postdegradation linear polymer solution from $170 \mathrm{cp}$ (for $0.3 \%$ PPG without nanomaterial) to a viscosity of $4437 \mathrm{cp}$ for $0.6 \%$ LXLG Nanocomposite PPG. This represents a $2510 \%$ viscosity increase (Table 1). Such tremendous viscosity increase was brought about by the incorporation of LXLG nanomaterial during PPG synthesis.

On thermal degradation/hydrolysis, LXLG nanocomposite PPG degrades, releasing a low molecular weight polymer solution and clay particles. These re-associate by a physical interaction after degradation, increasing the polymer solution viscosity massively. Thus, the invention provides a unique process integrating together the two sub-processes, nanocomposite PPG-based conformance control/gel treatment and polymer flooding, during an oil recovery operation with improved efficiency and operability.

Why this tremendous post-degradation viscosity increase? Clays are complex in nature. They have a high cation exchange capacity, surface area, surface reactivity, and adsorptive properties (Shibayama et al. 2004). As a result of this complex nature, chemical reactivity is usually high at clay surface. We hypothesize that, on thermal degradation, LXLG nanocomposite PPG degrades, releasing a low molecular weight polymer solution and clay particles. Strong interfacial interactions form between the degraded polymer matrix and reactive clay surface, causing an increased solution viscosity.

\subsection{Evaluation of LXLG Nanocomposite PPG Microstructure and Morphology, Before and After Degradation}

\subsubsection{Environmental Scanning Electron Microscopy Imaging of LXLG Nanocomposite PPG Before Its Degradation.}

A detailed microscopic study of LXLG nanocomposite hydrogel was done using an Environmental Scanning Electron Microscope (ESEM), and was compared against hydrogels 
with no nanomaterial. Studying the network structure of hydrogel is important because it gives us information about pore-interconnectivity. This information is useful in understanding the mechanisms of gel swelling behavior, gel strength after it swells, and perhaps even its thermal resistance ability. Figure 9a presents an ESEM micrograph of pure LXLG nanomaterial. Figure 9b presents an ESEM micrograph of pure polyacrylamide (PAM) polymer. Figure 9c presents a 3-D micrograph of bulk LXLG nanocomposite hydrogel. Figure 9d presents a micrograph of hydrogel with no nanomaterial. The micrographs of LXLG nanocomposite hydrogel are presented in Figures 9e to Figures 9g. The reason we present different micrographs of the nanocomposite gels is to show different sections of the material.

Comparing the pure Laponite XLG and pure polymer solution with the degraded nanocomposite gels, we infer that the thick network structure of the nanocomposite gel is as a result of the network structure observed in the pure polymer superimposed with the pure nanomaterial.

Contrasting the hydrogel with no nanomaterial versus the hydrogel with nanomaterial, (that is Figures 9d versus Figures $9 \mathrm{e}-\mathrm{g}$ ), we observe that although a porous interconnected network structure is seen in both nanocomposite and non-nanocomposite hydrogels, in LXLG nanocomposite hydrogels however (Figures 9e-g), the network structure is thicker, denser, and corrugated whereas in hydrogels with no nanomaterial, the network structure is finer, less dense, and smooth. Obviously, we say that the presence of nanomaterial in nanocomposite hydrogel affords this difference.

We are also quick to point out that when brine was used as the solvent, the network structure was extremely dense (Figure 9e) such that the pores in the network are almost closed up. However, this phenomenon was not observed when distilled water was used as the solvent. In 
an attempt to explain this phenomenon, we could only ascribe the presence of salt ions in the brine as a reason for this occurrence. A similar phenomenon was observed by Nelea et al. 2007. Lastly, Figures $9 \mathrm{~g}$ show to us that when this nanocomposite gels are stretched thin, a thinner network structure will be likewise observed.

\subsubsection{Environmental Scanning Electron Microscopy (ESEM) Imaging of LXLG Nanocomposite PPG After Its Degradation.}

After the hydrogels degraded, ESEM micrographs were again taken of the degraded sample. Figure 10a shows the micrograph of the degraded hydrogel with no nanomaterial. Figures $10 \mathrm{~b}$ and Figure 10c show the micrographs of a 1\% degraded LXLG nanocomposite gel. As is clearly seen in both non-nanocomposite (Figure 10a) and nanocomposite gel (Figures 10bc), the homogenous porous network structure that was initially observed before degradation disappears (collapses), signifying the degradation of the gel material into a polymer solution. In degraded gel without nanomaterial, the observed solution is less dense than in degraded gel with nanomaterial. This, we ascribe to the presence of nanomaterial in gel design.

Worthy of mention is a significant difference between Figures $10 \mathrm{~b}$ and Figures 10c. In Figure $10 \mathrm{~b}$, the initial network structure collapses into a ridge-like structure, whereas in Figures 10c, a block-like micrograph is observed. We lack sufficient knowledge to explain this occurrence. Characterization of hydrogel network is a complex process given its 3-dimensional complex nature and its frequent, dynamic changes to outside stimuli such as solvent, temperature, salinity, $\mathrm{pH}$ etc.

\subsection{Optical Microscopy Imaging of LXLG Nanocomposite PPG After Degradation}

After the LXLG nanocomposite PPG degraded, we utilized an optical microscope to help us understand the nature of the degraded nanocomposite material. Figure 11 presents an optical 
micrograph of a $0.2 \%$ LXLG Nanocomposite gel after degradation. Gel composition is $23 \%$ acrylamide, 100 ppm ammonium persulfate initiator and 625 ppm PEG crosslinker. We observed very small particles which were uniformly distributed across the entire sample and had an average size of about 1.5 microns. These smaller particles can travel deeper into the formation to mobilize additional oil.

\section{Discussion}

Preformed Particle Gels are often injected near wellbore to preferentially seal higher permeability zones or fractures, thus diverting injection water into low permeability unswept hydrocarbon-rich zones thereby sweeping oil from these. They can improve sweep efficiency in reservoirs and reduce excess water production by plugging high permeability zones during hydrocarbon production. The gel functions to reduce the permeability of the target zone to the flooding fluid, thus modifying the flow profile of the reservoir and diverting injected fluids into low-permeability zones with greater residual oil content. Over the last decade, the Chemistry of preformed particle gels has been greatly explored to modify gel properties and improve gel application.

The current work proposes an innovative product that increases oil recovery from mature oilfields by sequentially combining the processes of conformance control (gel treatment) and polymer flooding. This product, when injected into the reservoir, will initially act as a conformance control agent by plugging water-thief zones and channels, thereby directing injected water to sweep out oil from low permeability oil rich zones. After an extended time period, this product degrades into a highly viscous polymer solution which then moves into the deeper regions of the reservoir, mixes with flood water and increases its viscosity, and by so doing improves water and polymer flooding processes by increasing water sweep efficiency, 
thereby enhancing oil production. Thus, with a single product, we can: (a) correct reservoir heterogeneity and improve conformance control, (b) improve water flooding process and, (c) boost polymer flooding. The obvious advantage of this is tremendous cost savings! Costs associated with the above three EOR methods will be significantly reduced by the application of this single product.

\section{Conclusion}

- A degradable nanocomposite hydrogel have been synthesized using Laponite XLG as nanomaterial, and evaluated for mobility control and fracture-plugging applications in mature reservoirs.

- It was observed that gel strength increased with increasing nanomaterial concentration.

- It was also observed that longterm thermal stability of hydrogels was directly proportional to nanomaterial concentration. The higher the nanomaterial concentration, the longer the thermal stability of the hydrogels.

- Post-degraded nanocomposite hydrogel viscosity measurements were 26 times higher than those of hydrogels without nanomaterial. After degradation, LXLG nanocomposite hydrogel had a post-degradation viscosity (4437 cp), whereas hydrogel without nanomaterial had a post-degradation viscosity of $170 \mathrm{cp}$.

- LXLG nanocomposite hydrogel can be used for conformance control applications because they have higher strengths and longterm thermal resistance than hydrogels without nanomaterial.

- For secondary polymer flooding- mobility control applications, we recommend using degradable LXLG nanocomposite hydrogels, since they have a high post-degradation viscosity under anaerobic conditions. 
- This product, when injected into the reservoir, will initially act as a conformance control agent by plugging water-thief zones and channels, thereby directing injected water to sweep out oil from low permeability oil rich zones. After an extended time period, this product degrades into a highly viscous polymer solution which then moves deeper into the reservoir, mixes with flood water and increases its viscosity, and by so doing improves water and polymer flooding processes by increasing water sweep efficiency, thereby enhancing oil production. Thus, with a single product, we can (a) correct reservoir heterogeneity and improve conformance control, (b) Improve water flooding process and (c) boost polymer flooding.

\section{Acknowledgements}

Funding for this project is provided by RPSEA through the "Ultra-Deepwater and Unconventional Natural Gas and Other Petroleum Resources" program authorized by the U.S. Energy Policy Act of 2005. RPSEA (www.rpsea.org) is a nonprofit corporation whose mission is to provide a stewardship role in ensuring the focused research, development and deployment of safe and environmentally responsible technology that can effectively deliver hydrocarbons from domestic resources to the citizens of the United States. RPSEA, operating as a consortium of premier U.S. energy research universities, industry, and independent research organizations, manages the program under a contract with the U.S. Department of Energy's National Energy Technology Laboratory. 


\section{References}

Asghari, K., 1999. Evaluating Gel Systems for Permeability Modification Purposes in Carbon Dioxide Flooding Processes and Investigating the Fluid Flow through Hydrogels. PhD Dissertation, University of Kansas, Lawrence, KS.

Bai, B., Li, Y., Liu, X., 1999. New Development of Water Shutoff and Profile Control in Oilfields in China. Oil Drilling \& Production Technology, 20, 3.

Bai, B. 2001. Gel Treatment Technology for Fracture Reservoirs. A paper presented at the $11^{\text {th }}$ Water Control Symposium of China Oilfields, Dandong, Liaoning Province, 27-31 July 2001.

Bai, B., Li, L., Liu, Y., Liu, H., Wang, Z., You, C., 2007a. Preformed Particle Gel for Conformance Control: Factors Affecting its Properties and Applications. SPE Reservoir Evaluation \& Engineering. 10, 4, 415-422.

Bai, B., Liu, Y., Coste, J.P., Li, L., 2007b. Preformed Particle Gel for Conformance Control: Transport Mechanism through Porous Media. SPE Reservoir Evaluation \& Evaluation, 10, 176.

Bai, B., Huang, F., Liu, Y., Seright, R.S., Wang, Y., 2008. Case Study on Preformed Particle Gel for In-depth Fluid Diversion. Paper SPE 113997 presented at the SPE/DOE Symposium on Improved Oil Recovery, Tulsa, April 19-23.

Bai, B., Wei, M. and Liu, Y., 2013, Field and Lab Experience with a Successful Preformed Particle Gel Conformance Control Technology. Paper SPE 164511 presented at the SPE Production and Operations Symposium, Oklahoma City, Oklahoma, USA.

Bryant, S.L., Rabaioli, M.R., Lockhart, T.P. 1996. Influence of Syneresis on Permeability Reduction by Polymer Gels. SPE 35446-PA. SPE Production \& Facilities, 11, 4, 209-215. 
Frampton, H., Morgan, J., Cheung, S., Munson, L., Chang, K. and Williams, D., 2004, Development of a Novel Waterflood Conformance Control System. Paper SPE 89391 presented at the SPE/DOE 14th Symposium on IOR, Tulsa, OK, USA.

Kytai, T. N., Jennifer L. W. 2002, Photopolymerizable Hydrogels for Tissue Engineering Applications. Biomaterials, 23, 4307-4314

Liu, B.; Bai, B.; Li, Y. 1999. Research on Preformed Gel Grains for Water Shutoff and Profile Control. Oil drilling and Production Technology 21, 3.

Liu, Y., Zhu, M., Liu, X., Zhang, W., Sun, B., Chen, Y., Hans-Juergen, P.A. 2006. High Clay Content Nanocomposite Hydrogels with Surprising Mechanical Strength and Interesting Deswelling Kinetics. Polymer. 47, 1-5.

Nelea, M., Hoemann, C.D., Shive, M.S., Chenite, A., Buschmann, M.D. 2007. Ultrastructure of Chitosan-Glycerol Phosphate Hydrogels by ESEM. Microsc Microanal 13(Suppl). DOI: 10.1017/S1431927607073357, 472 CD-473CD

Seright, R.S., 1988. Placement of Gel to Modify Injection Profiles. SPE 17332 presented at the SPE/DOE Enhanced Oil Recovery Symposium, Tulsa, OK, pp. 137-148.

Seright, R.S. 1990. Impact of Dispersion on Gel Placement for Profile Control. Paper SPE 20127 presented at the 1990 SPE Permian Basin Oil and Gas Recovery Conference, Midland, March 8-9.

Shibayama, M., Suda, J., Karino, T., Okabe, S., Takehisa, T., Haraguchi, K. 2004. Structure and Dynamics of Poly(N-isopropylacrylamide)-Clay Nanocomposite Gels. Macromolecules, 37, 9606-9612.

Tongwa, P., Nygaard, R., Bai, B. 2013. Evaluation of a Nanocomposite Hydrogel for Water Shut-off in Enhanced Oil Recovery Applications: Design, Synthesis, and Characterization. Journal of Applied Polymer Science, 128, 787-794. 
Tongwa, P., Nygaard, R., Aaron, B., Bai, B. 2013. Evaluation of Potential Fracture-Sealing Materials for Remediating $\mathrm{CO}_{2}$ Leakage Pathways during $\mathrm{CO}_{2}$ Sequestration. International Journal of Greenhouse Gas Control, JGGC-D-13-00044R1.

Vossoughi, S. 2000. Profile Modification using In-situ Gelation Technology-a Review. Journal of Petroleum Science and Engineering, 26, 199-209.

Wang, H.G., Guo, W.K., Jiang, H.F. 2001. Study and Application of Weak Gel System Prepared by Complex Polymer Used for Depth Profile Modification. Paper SPE 65379 presented at the SPE International Symposium on Oilfield Chemistry, Houston, 13-16 February. DOI: 10.2118/65379-MS.

Wang, W., Liu, Y., Gu, Y. 2003. Application of A Novel Polymer System in Chemical Enhanced Oil Recovery (EOR). Colloid and Polymer Science, 281(11), 1046-1054.

Wen-Fu, L., Sung-Chuan, L. 2006. Effect of Hydrotalcite on the Swelling and Mechanical Behaviors for the Hybrid Nanocomposite Hydrogels Based on Gelatin and Hydroltalcite. Journal of applied Polymer Science. 100, 500-507.

Willhite, G.P., Green, D.W., Young, T.S., Thiele, J.L., Michnick, M.J., Vossoughi, S., Terry, R.E., 1986. Evaluation of Methods of Reducing Permeability in Porous Rocks by In Situ Polymer Treatment — Final Report. DOErBCr10354-16_DE86000-264., NTIS, U.S. Department of Commerce, Springfield, VA, February.

Young, T.S., Willhite, G.P., Green, D.W. 1988. Study of Intra Molecular Crosslinking of Polyacrylamide in $\mathrm{Cr}$ (III)-Polyacrylamide Gelation by Size-Exclusion Chromatography, Low-Angle Laser Light Scattering, and Viscometry. Water-Soluble Polymers for Petroleum Recovery, G.A. Stahl and D.N. Schulz (eds.), Plenum Press, New York City, $329-42$.

Zhang, H., Bai, B. 2011. Preformed-Particle-Gel Transport through Open Fractures and Its Effect on Water Flow. SPE Journal, 16, 2, 388-400 


\begin{tabular}{|c|c|c|}
\hline $\begin{array}{c}\text { In-Situ } \\
\text { Gels }\end{array} \longrightarrow \begin{array}{l}\text { Preformed } \\
\text { Gels }\end{array} \longrightarrow \begin{array}{l}\text { Nanocomposite } \\
\text { Preformed Gels }\end{array} \longrightarrow \begin{array}{l}\text { Degradable } \\
\text { Nanocomposite Preformed } \\
\text { Gels }\end{array}$ \\
\hline
\end{tabular}

Prior technology $\longrightarrow$ Current technology $\longrightarrow$ Current technology $\longrightarrow$ Future technology
(Seright, 1988)
(Bai, 2001)
(Bai, 2007a)

Fig.1- Progress in gel development for conformance control. 
(a). Initially, excess water production exists from fractures or high permeability zones of reservoir.

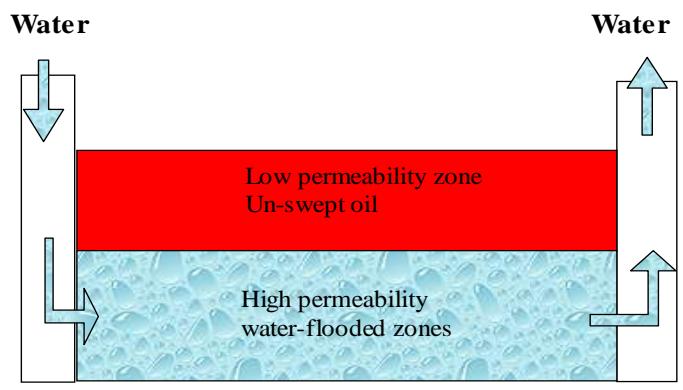

(a)

(b). On initial injection into reservoir, nanocomposite PPG serves to plug high permeability near well-bore zones, diverting injected water to sweep out oil from low permeability region.

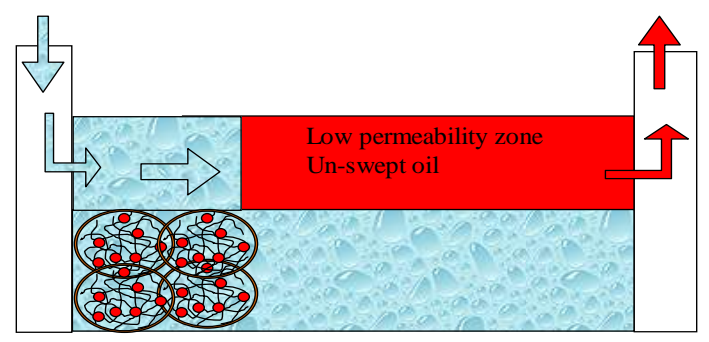

(b)

(c). After an extended time period, nanocomposite PPG degrades into highly viscous polymer solution that moves into deeper regions of reservoir to increase the viscosity of flood water and hence boost polymer flooding. Oil production is thus increased.

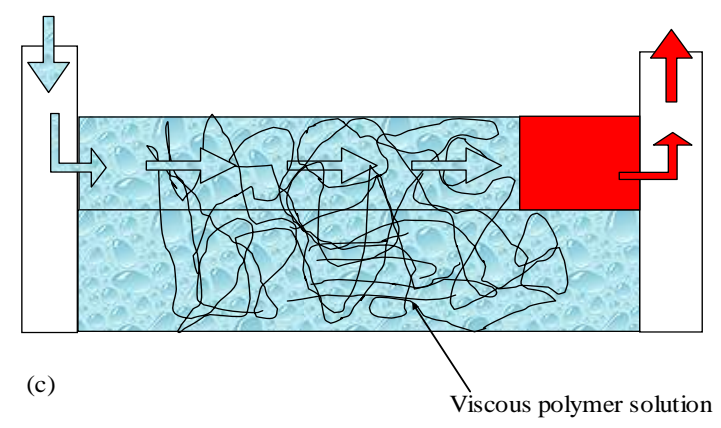

Fig.2-Degradable nanocomposite preformed particle gel for improved mobility control and effective volumetric sweep efficiencies in heterogeneous reservoirs. 

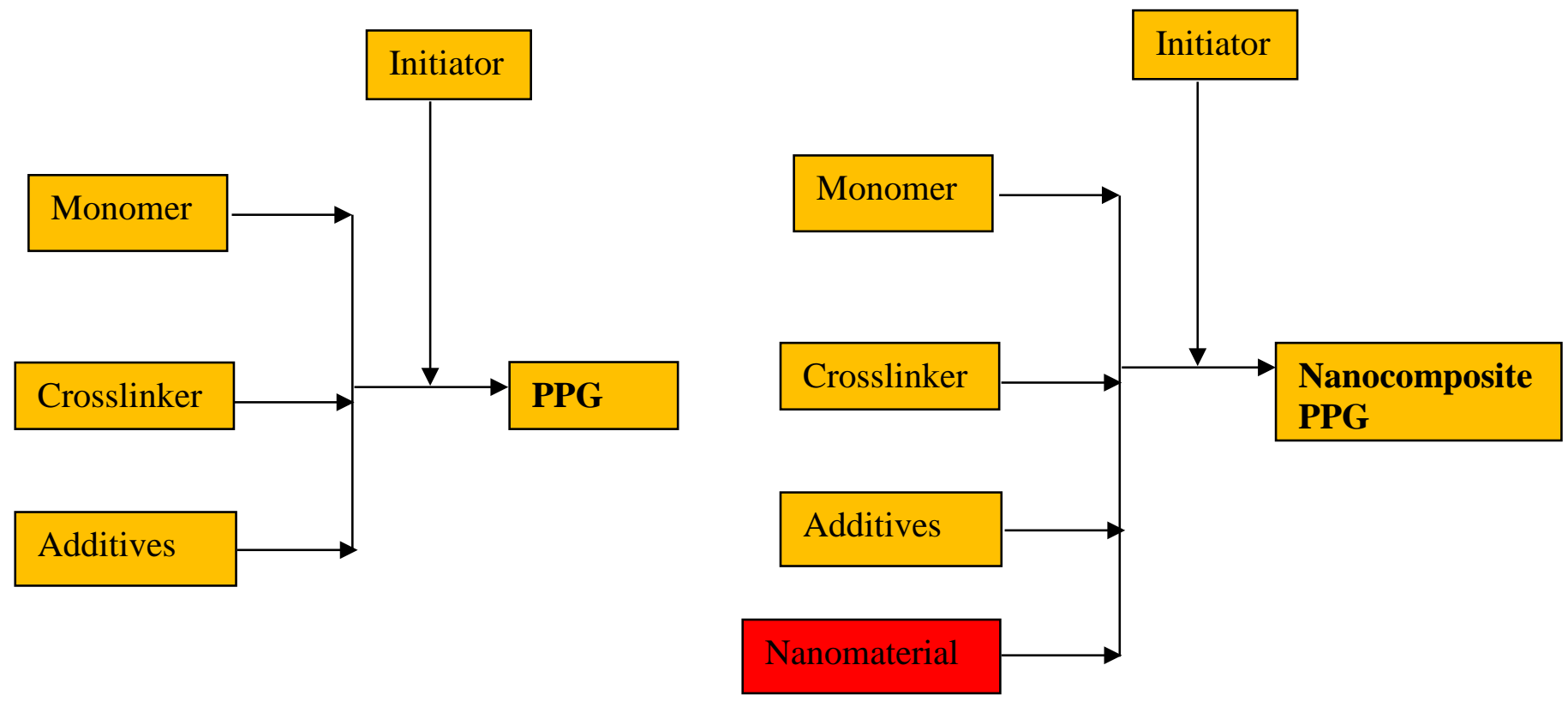

a. Existing preformed gel technology

b. Proposed nanocomposite gel technology

Fig 3-Synthesis of existing and proposed preformed gel technology. 


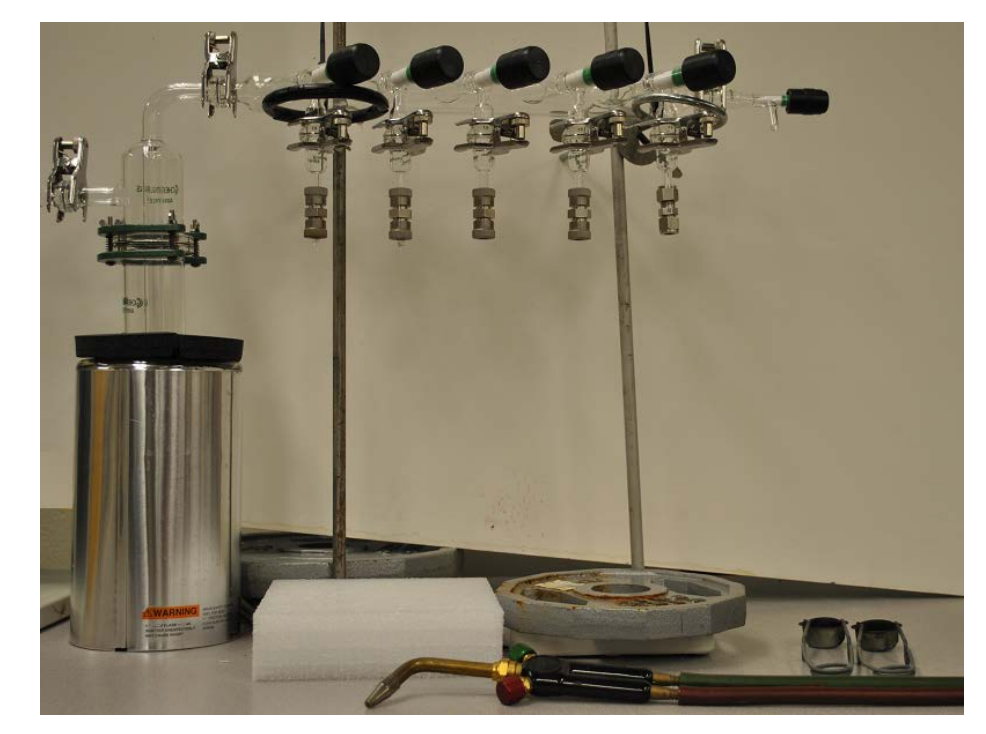

Figure 4

\title{
Figure 4
} 4

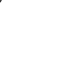

\begin{abstract}
Fig.4-Manifold used to seal ampoule
-
\end{abstract}
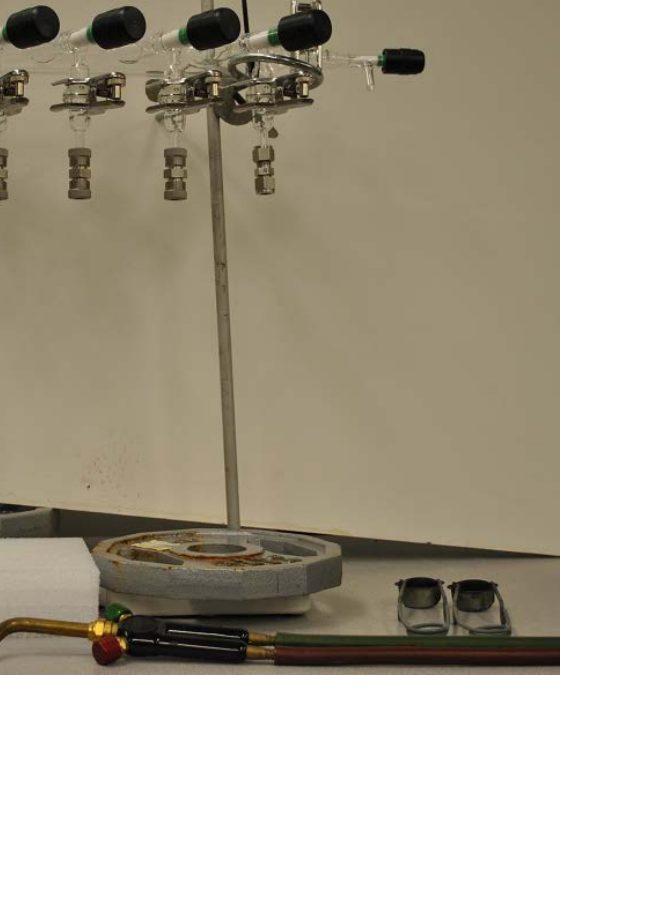


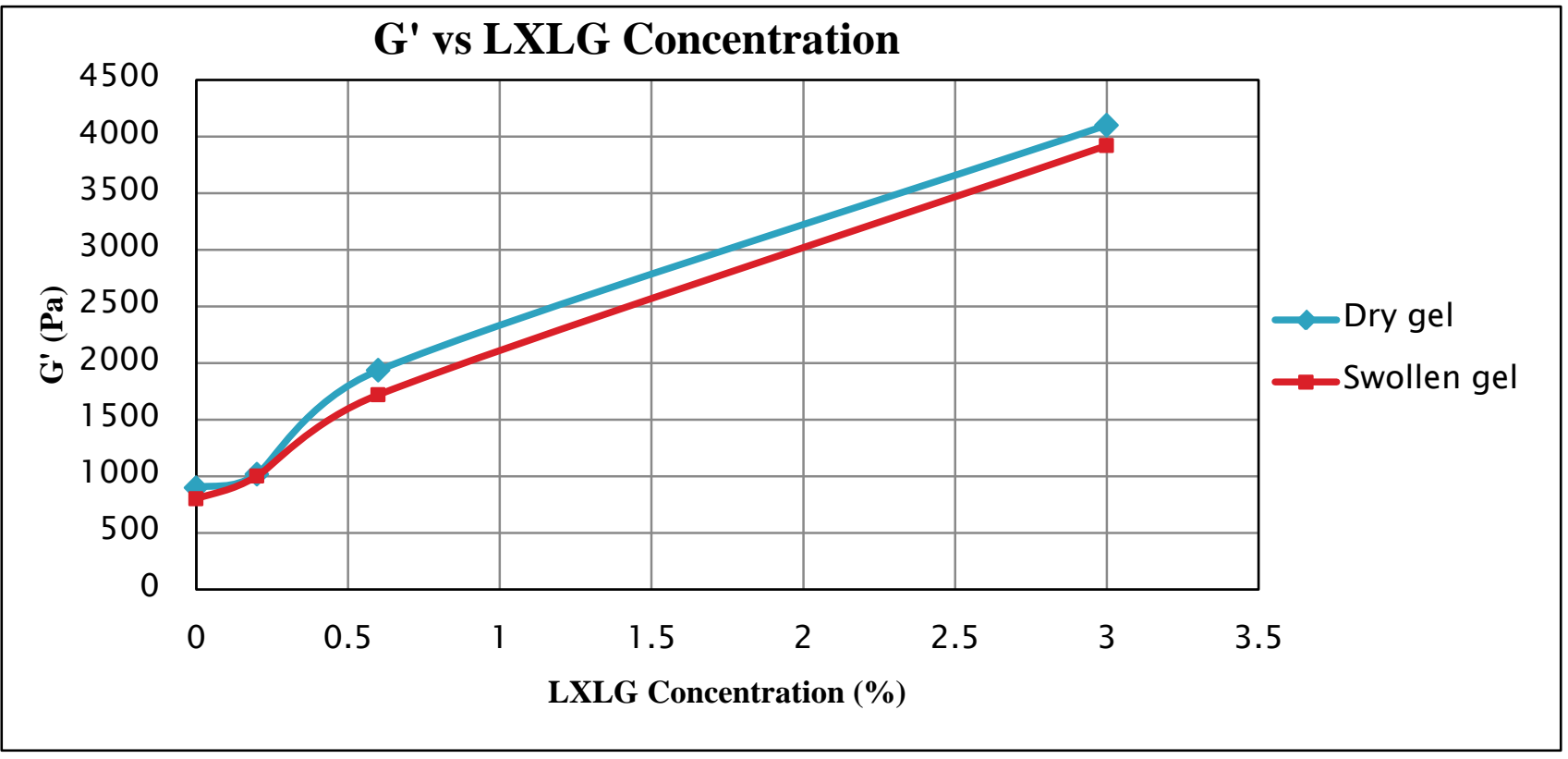

Fig. 5-A clear improvement in hydrogel mechanical strength is observed between gels with nanomaterials and those without nanomaterials. Gel strength was observed to increase with increase in nanomaterial concentration. Measurements were done for both dry and swollen gels. 
Fiqure 7

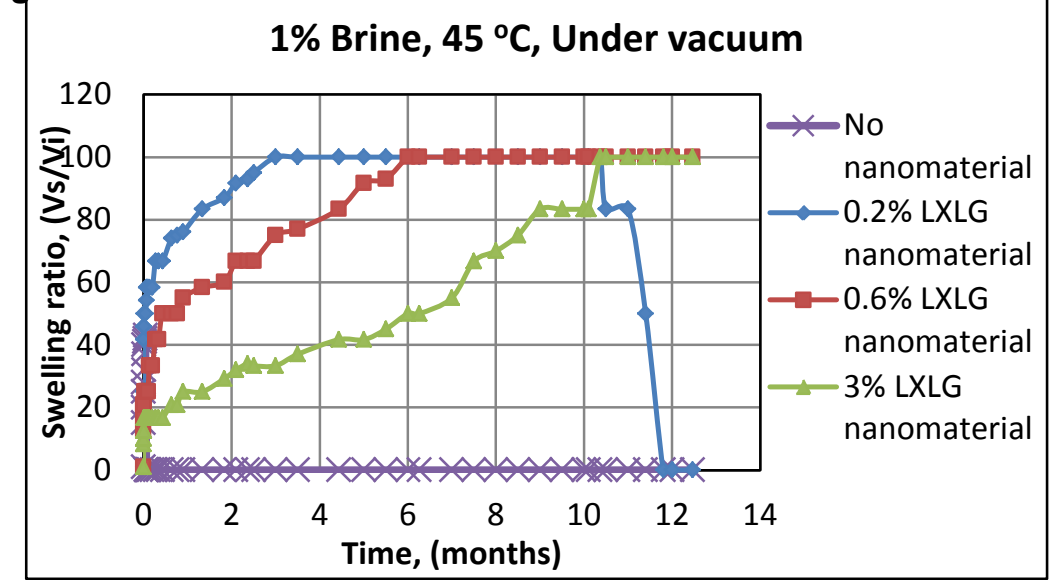

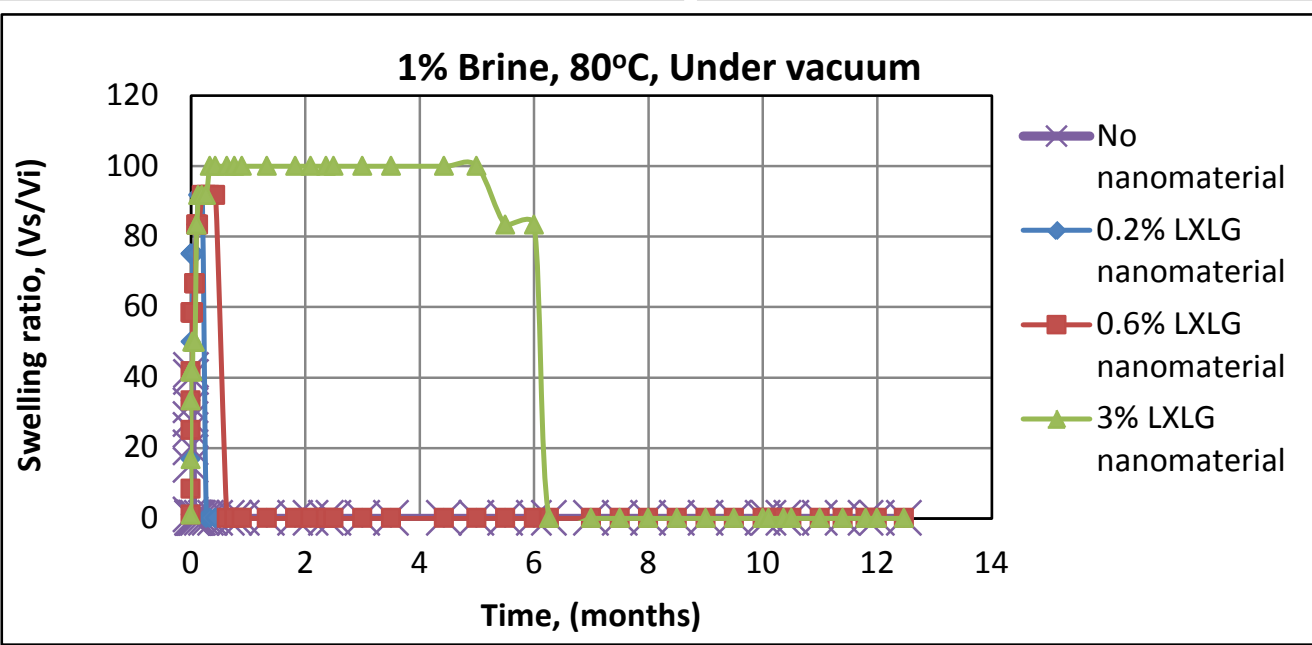

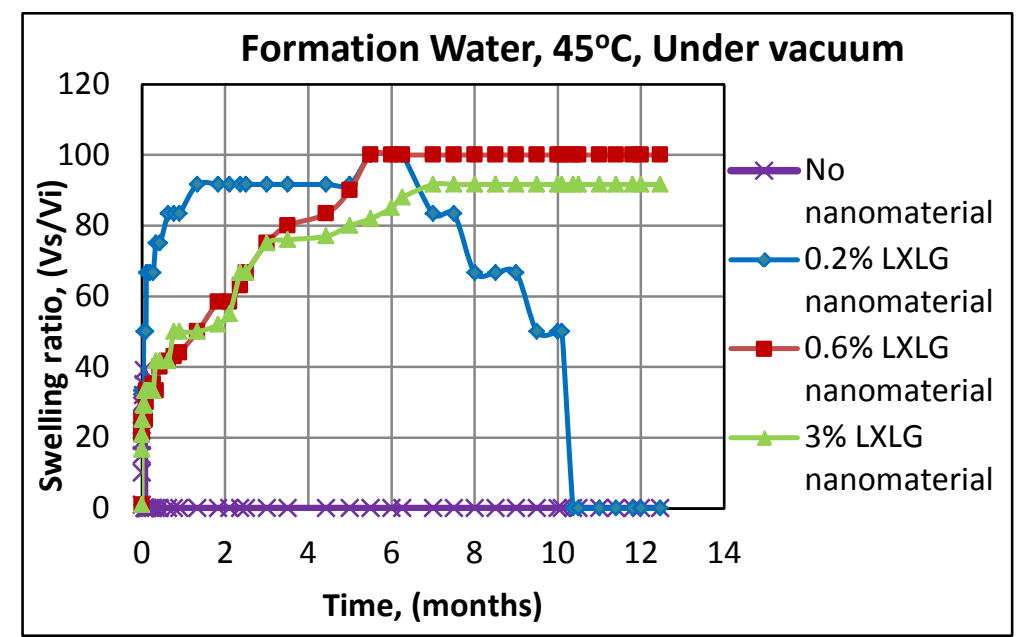

Formation Water, $60^{\circ} \mathrm{C}$, Under vacuum

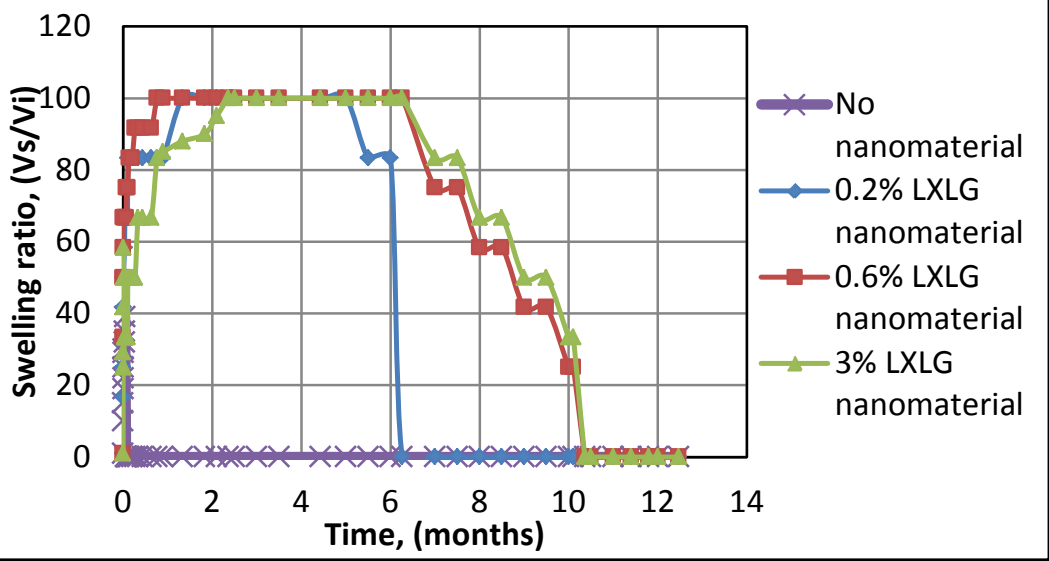

(b)

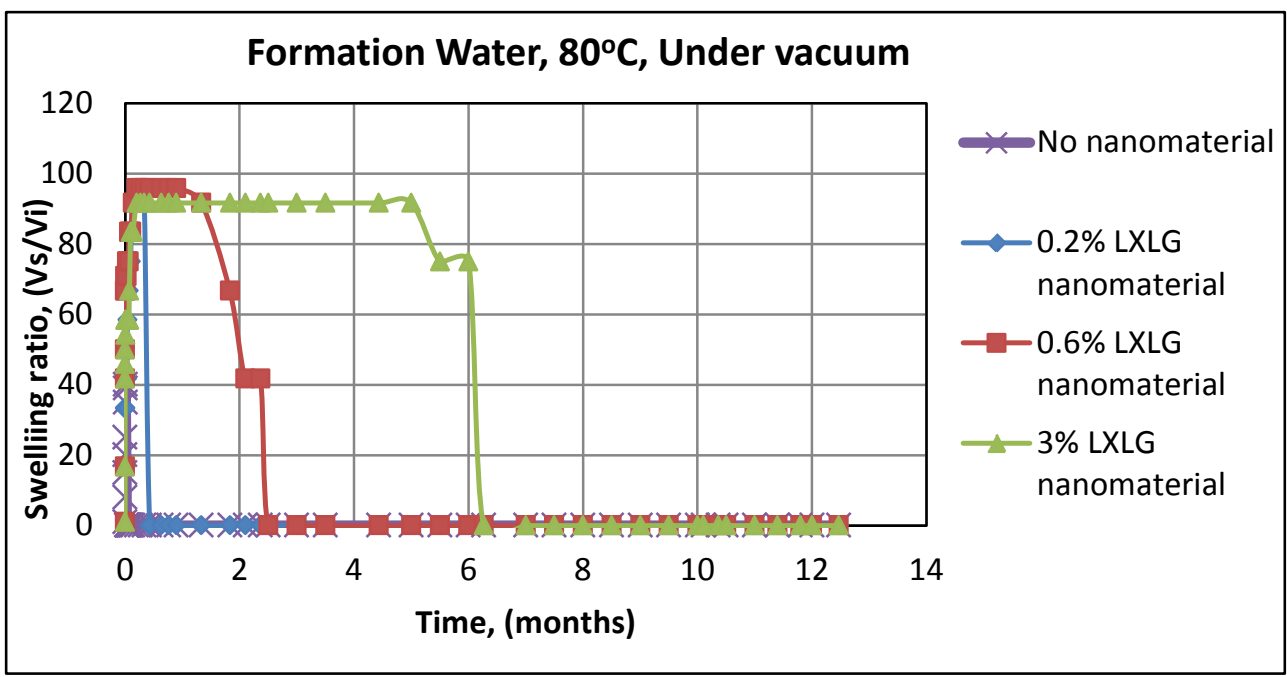


Fig. 7-Longterm thermal stability of LXLG nanocomposite hydrogels under anaerobic conditions and In (a): $1 \%$ brine solution and (b): Formation water. The more the nanomaterial concentration, the longer the time it took for gel to degrade. 
Under Aerobic Environment

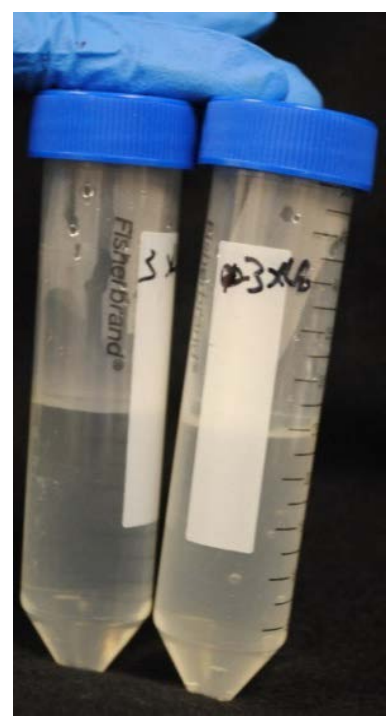

Before degradation
After degradation
Under Anaerobic Environment

(b)

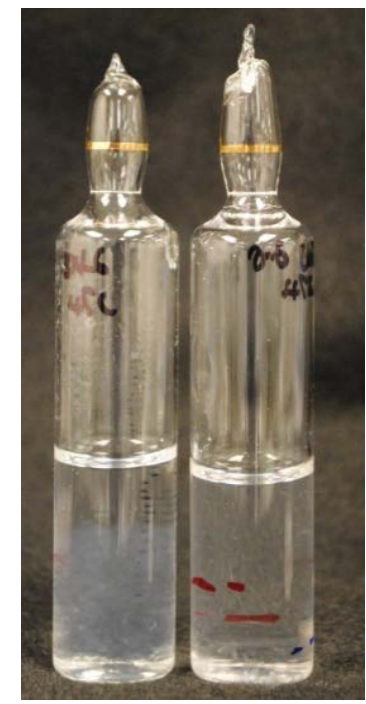

Before

After

degradation degradation

Fig. 8-(a) Aerobic Environment: LXLG nanocomposite gel Sample before and after it degrades into a polymer solution. (b) Anaerobic environment: LXLG nanocomposite gel sample before and after it degrades into a polymer solution. 


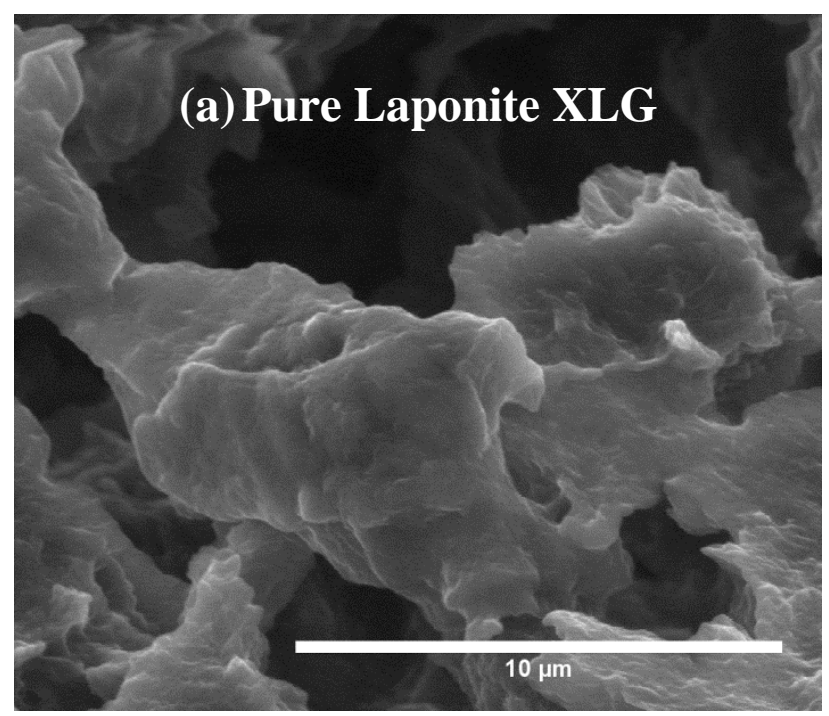

(a)-Pure Laponite XLG solution

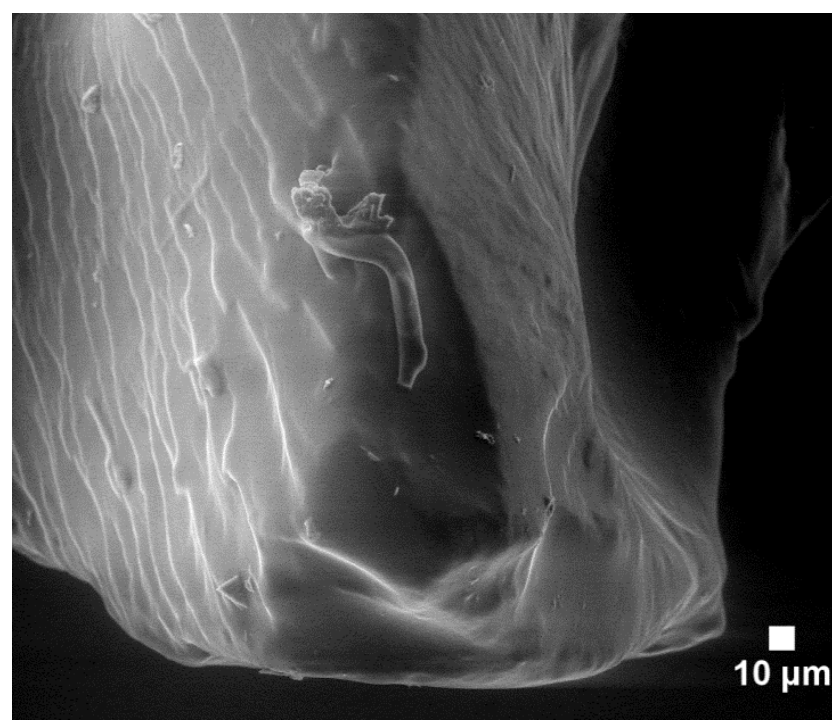

(c)- 3-D bulk micrograph of LXLG nanocomposite hydrogel.

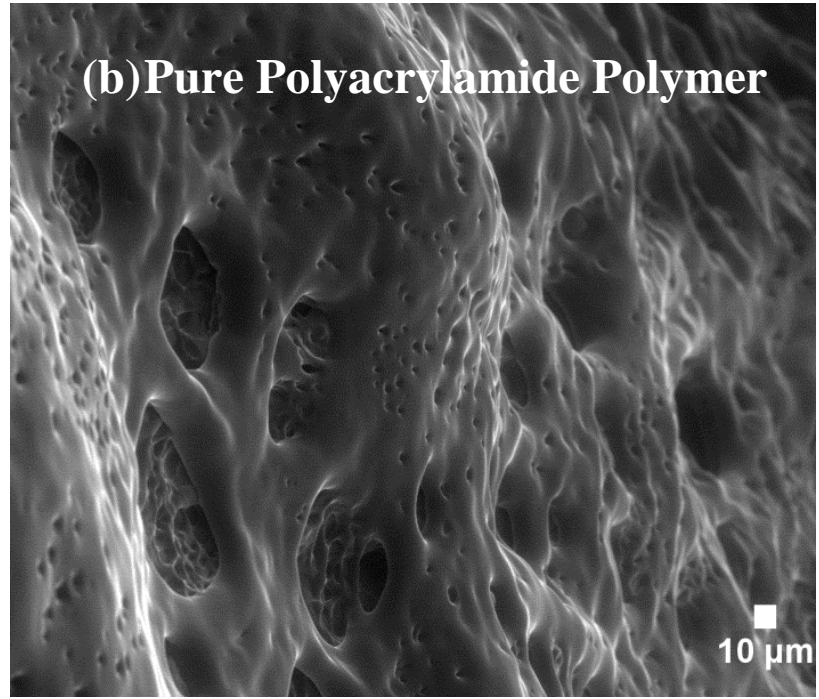

(b)-Pure polyacrylamide polymer (PAM) solution

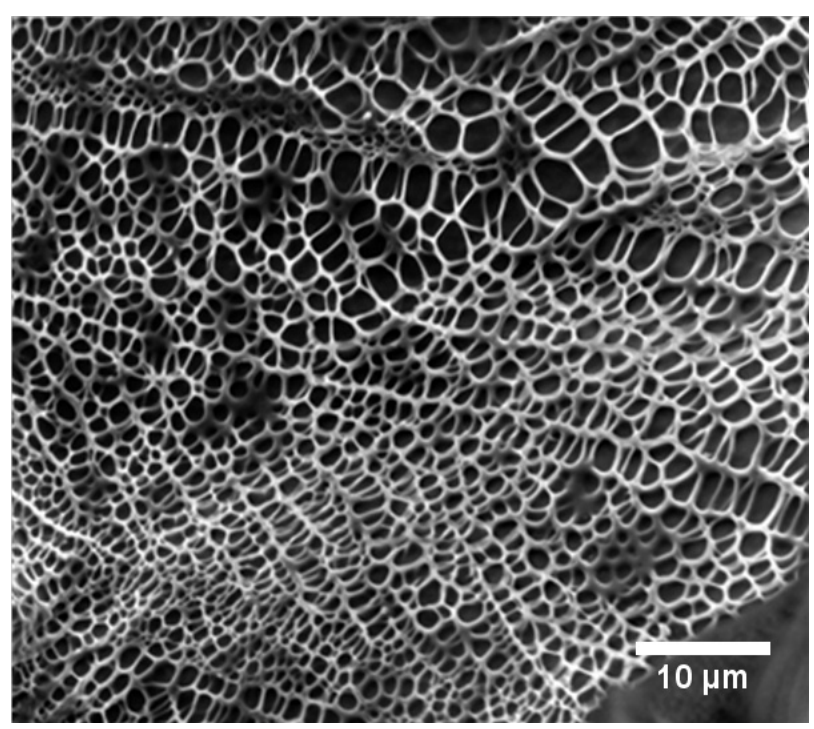

(d)-Fine, smooth network structure of hydrogel with no nanomaterial (Jia, 2011). 

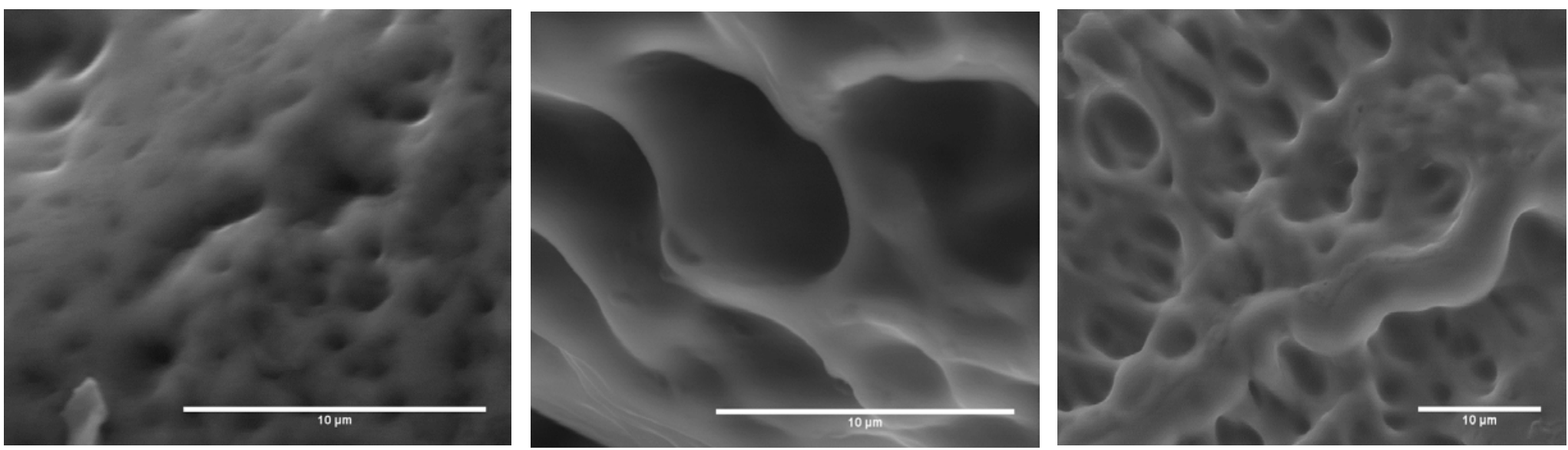

(e)-Very thick and dense network structure of LXLG nanocomposite gel swelled in $1 \%$ brine as solvent.
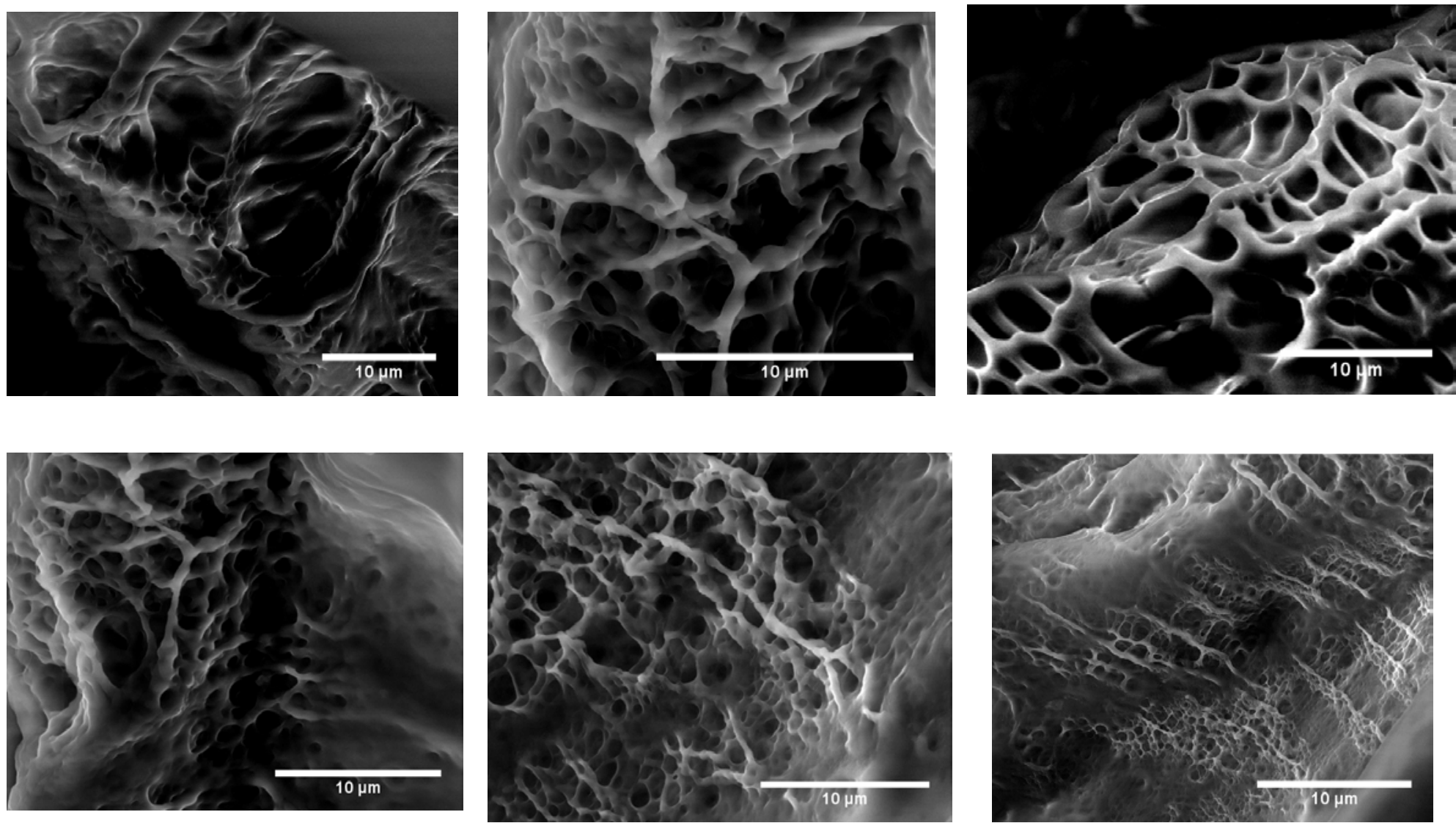

(f)-Corrugated and very thick network structure of LXLG nanocomposite gel swelled in distilled water as solvent. 

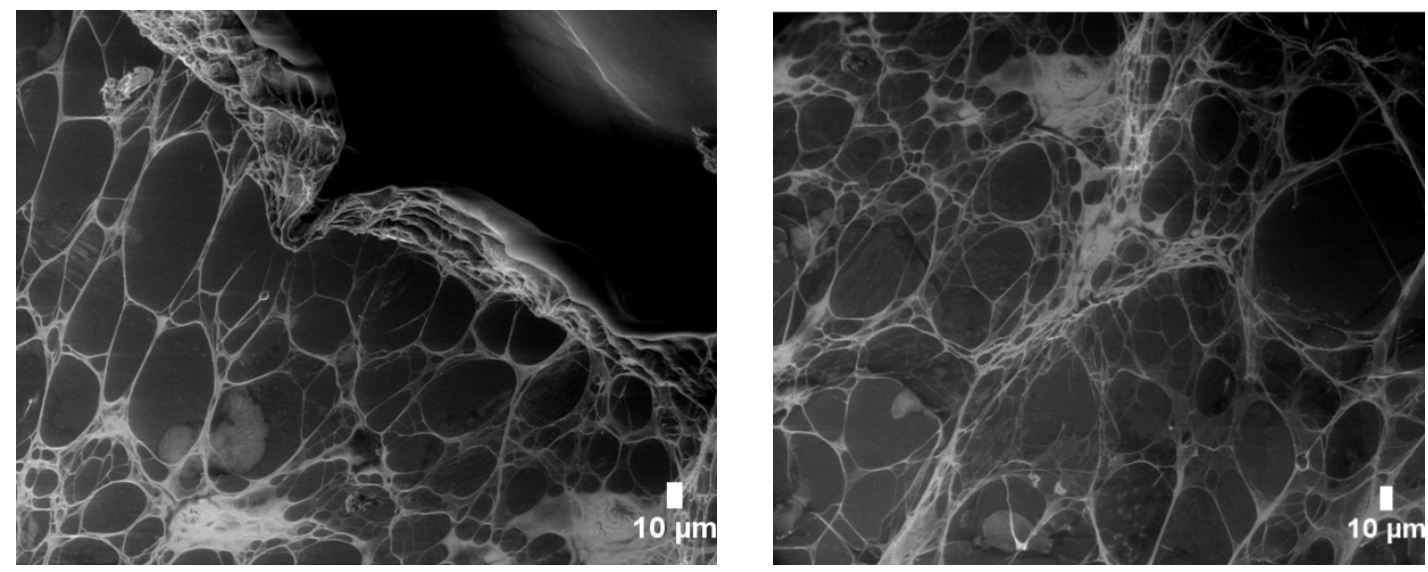

(g)-Network structure of an extremely stretched, thin section of LXLG nanocomposite hydrogel Swelled in distilled water.

Fig.9-Before-degradation Environmental Scanning Electron Microscopy (ESEM) micrographs of: (a) Pure LXLG nanomaterial. (b) Pure polyacrylamide (PAM) polymer. (c) 3-D micrograph of bulk LXLG nanocomposite hydrogel. (d) Hydrogel with no nanomaterial. A fine, smooth network structure is observed. (e) LXLG nanocomposite hydrogel swelled in $1 \%$ brine as the solvent. The presence of brine almost caused the porous network to close up. (f) LXLG nanocomposite hydrogel swelled in distilled water as the solvent. A denser, thicker, and corrugated network structure is observed. (g) An extremely stretched, thin section of LXLG nanocomposite hydrogel. 


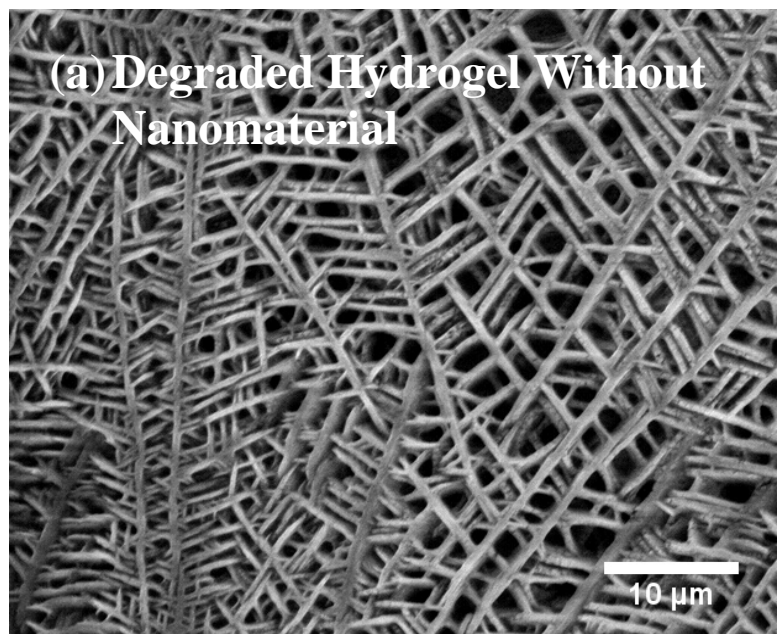

(a)-Degraded hydrogel with no nanomaterial (Jia, 2011)
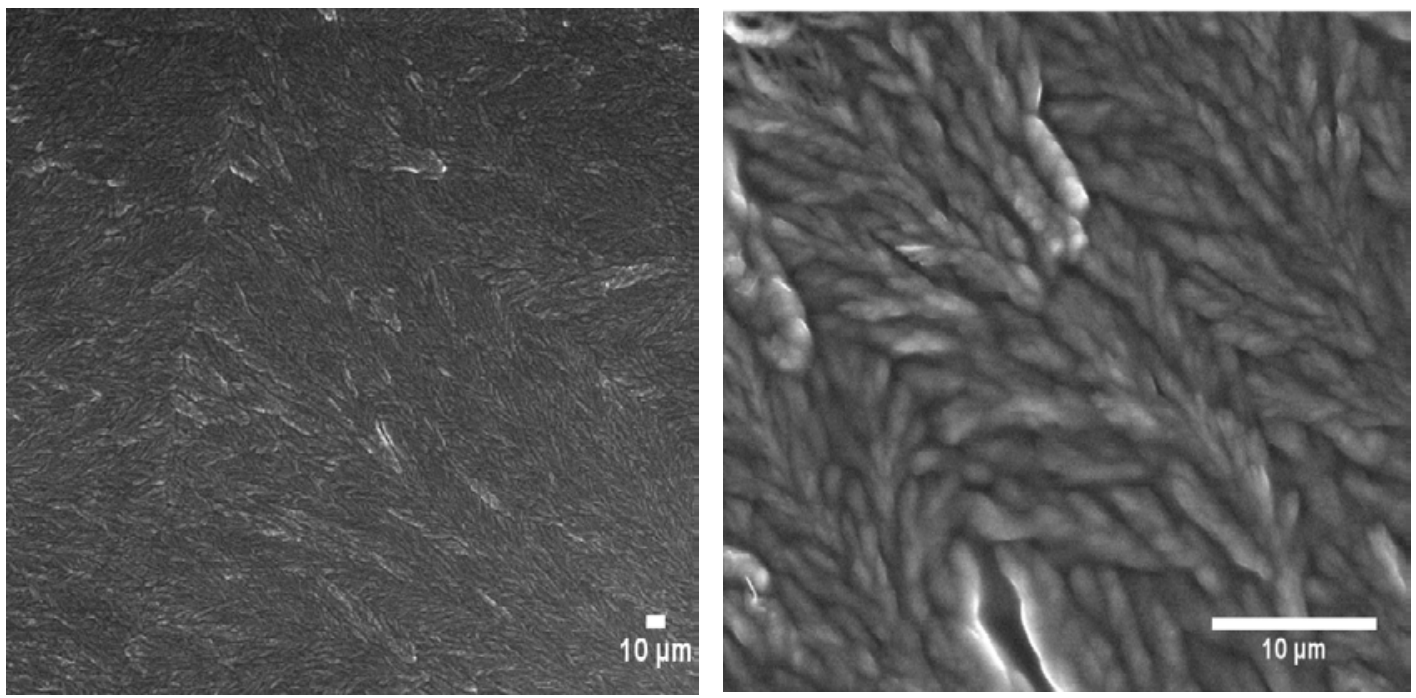

(b)-Degraded 1\% LXLG nanocomposite hydrogel: ridge-like structure is observed
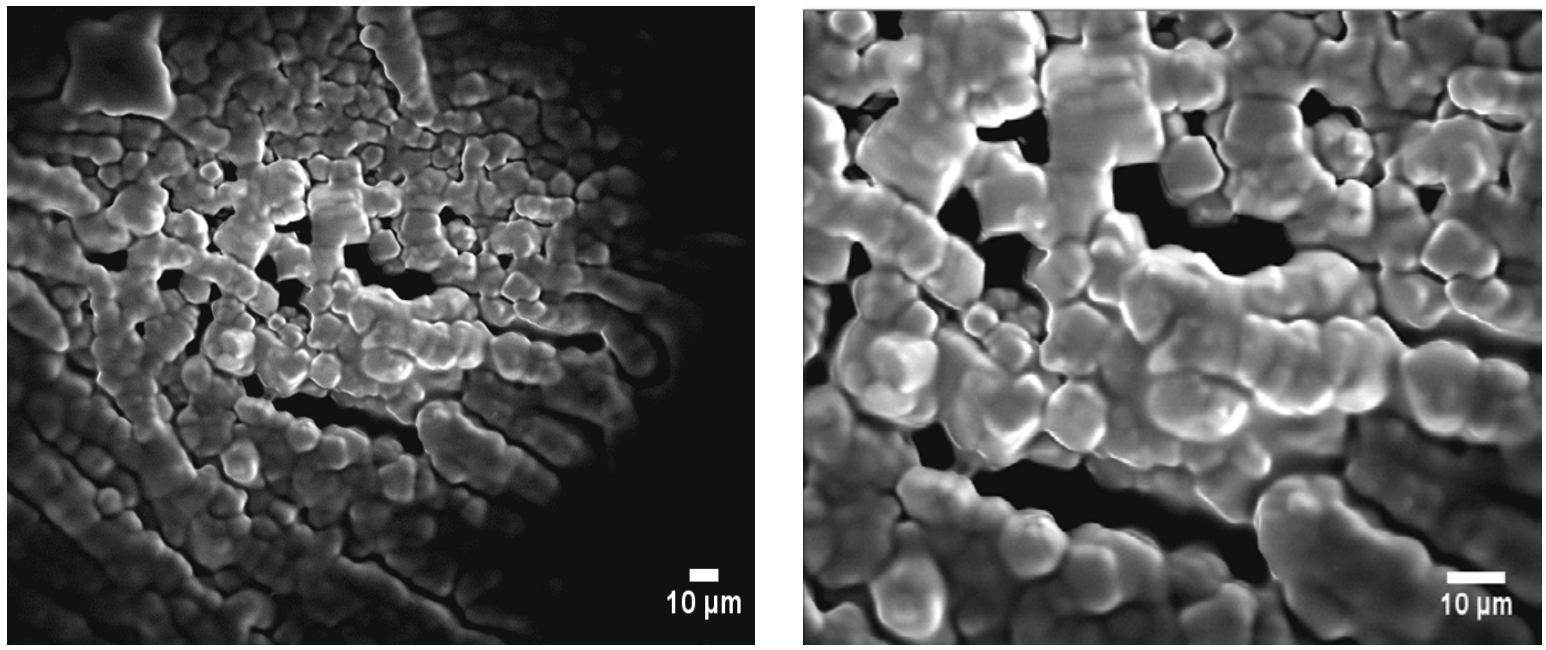

(c)-Degraded 1\% LXLG nanocomposite hydrogel: block-like structure is observed 
Figure 10. After-degradation Environmental Scanning Electron Microscopy (ESEM) Micrographs of: (a) Degraded hydrogel with no nanomaterial. (b) A $1 \%$ degraded LXLG nanocomposite gel. Here the initial network structure collapses into a ridge-like structure. (c) A 1\% degraded LXLG nanocomposite gel. Here the initial network structure collapses into a block-like structure. We lack sufficient knowledge to explain this occurrence. Characterization of hydrogel network is a complex process given its 3-Dimensional complex nature and its frequent, dynamic changes to outside stimuli such as solvent, temperature, salinity, pH etc. 


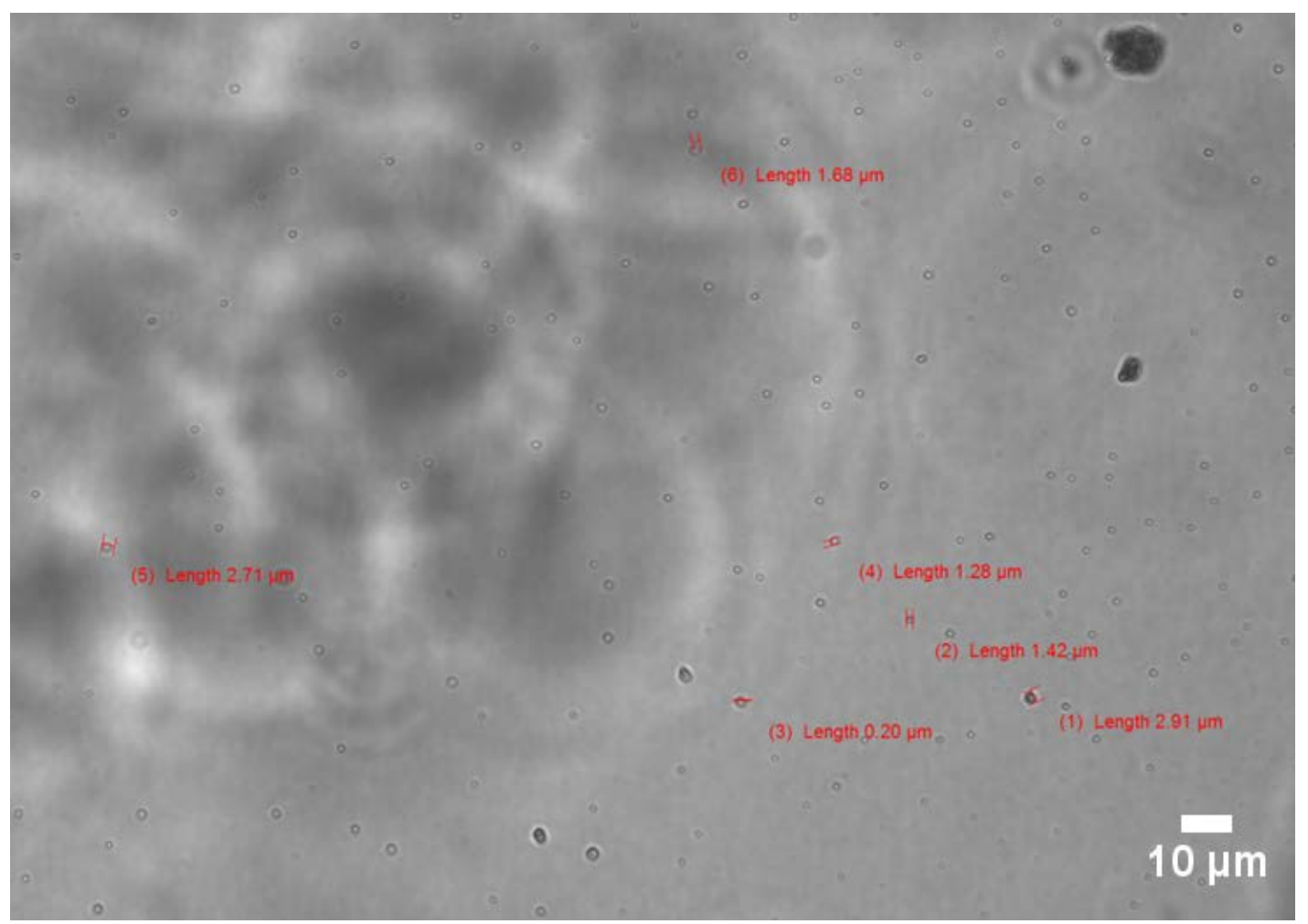

Fig.11-Optical Micrographs of degraded 0.2\% LXLG nanocomposite PPG. Tiny particles with an average size of $\mathbf{1 . 5}$ microns were seen throughout the sample. 
Table 1. Viscosity measurements for pure polymer, pure LXLG nanomaterial, and degraded LXLG nanocomposite PPG.

\begin{tabular}{|c|c|c|c|c|c|}
\hline \multirow{2}{*}{$\begin{array}{c}\text { Concentration } \\
(\%)\end{array}$} & $\begin{array}{c}\text { Polyacrylamide } \\
\text { Polymer } \\
\text { (PAM) }\end{array}$ & $\begin{array}{c}\text { Pure LXLG } \\
\text { Nanomaterial }\end{array}$ & \multicolumn{2}{|c|}{$\begin{array}{c}\text { Degraded LXLG } \\
\text { Nanocomposite PPG }\end{array}$} & $\begin{array}{c}\text { Degraded PPG } \\
\text { with No } \\
\text { Nanomaterial }\end{array}$ \\
\cline { 2 - 5 } & Viscosity, (cp) & Viscosity, (cp) & $\begin{array}{c}\text { Viscosity, } \\
\text { (cp) - } \\
\text { Aerobic }\end{array}$ & $\begin{array}{c}\text { Viscosity, } \\
\text { (cp) - } \\
\text { Anaerobic }\end{array}$ & $\begin{array}{c}\text { Viscosity, (cp) } \\
(0.3 \%)\end{array}$ \\
\hline $0.2 \%$ & 30.6 & 2 & 20 & 1113 & \multirow{2}{*}{170} \\
\hline $0.6 \%$ & 107.2 & 3 & 39.7 & 4437 & \\
\hline $1 \%$ & 353.5 & 3.7 & 612.5 & -- & \\
\hline $3 \%$ & 6303 & 4.5 & 3069 & 7563 & \\
\hline $5 \%$ & 48340 & 10 & 6982 & -- & \\
\hline
\end{tabular}

